\title{
Menstruación y atabaques: una aproximación a las prácticas musicales del candomblé afro-bahiano
}

\section{Menstruation and atabaques: an approximation to the musical practices of afro-bahian candomblé}

ARTÍCULO

\author{
María Gil de Muro \\ Universidad de Buenos Aires, Argentina. Contacto: gildemurom@gmail.com
}

Recibido: agosto de 2021

Aceptado: octubre de 2021

\section{Resumen}

La música en el candomblé afro-bahiano es central para llevar a cabo las ceremonias rituales. En este contexto, los atabaques consagrados son los encargados de llamar a las divinidades y promover el trance. La ejecución de los ilus es potestad de los ogãs, un puesto exclusivamente masculino, de gran jerarquía y prestigio dentro y fuera del terreiro, mientras que las mujeres no pueden acceder a este puesto por un tabú vinculado a la menstruación.

A partir del trabajo de campo realizado en varios terreiros de Salvador de Bahía y el relevamiento de diversos testimonios, este artículo propone un acercamiento a la participación que tienen las mujeres dentro de la casa de santo, los reparos socioculturales que existen sobre la menstruación dentro de esta comunidad y las posibles interpretaciones respecto a la prohibición que cae sobre las mujeres de tocar los ilus consagrados en las ceremonias rituales.

Palabras clave: Candomblé, mujeres, tambores, menstruación.

\section{Abstract}

The music in the afro-bahian candomblé is central to ritual ceremonies. In this context, the consecrated atabaques perform the task of calling the deities and promoting the trance. The execution of the ilus is in custody of the ogãs, an exclusively masculine role, high in hierarchy and very prestigious inside and outside the terreiro, while women have no access to this position because of a taboo related to menstruation.

Based on field work done in several terreiros in Salvador de Bahia and the examination of diverse testimonies, this article proposes an approach to the participation of women inside the temple, the socio-cultural objections that exist concerning menstruation in the 
community and the possible interpretations regarding the prohibition that impedes women from playing the consecrated ilus in the ritual ceremonies.

Keywords: Candomblé, women, drums, menstruation.

\section{Introducción}

El candomblé de Salvador de Bahía forma parte de las religiones de la diáspora africana en América Latina (Johnson y Palmié, 2018). En Brasil, candomblé es una denominación que señala un tipo de estructura religiosa genérica, engloba diferentes manifestaciones de ascendencia africana representadas en los terreiros o casas de santo (Hodge Limonta, 2009, p.25), y tiene su paralelo en los Xangôs de Pernambuco y en el Batuque de Rio Grande do Sul, entre otros. Se trata de una religión que se caracteriza por tener una serie de rituales de iniciación, prácticas de posesión y un conjunto de divinidades. Éstas, conocidas como orixás, se manifiestan en los hijos e hijas de santo. Cada casa de santo o terreiro está organizada según una jerarquía en la que confluyen años de trayectoria, aprendizajes y rituales de pasaje. Quien conduce el terreiro es la mãe o pai de santo, o iyalorixá o babalorixá.

Existen diversas variantes de candomblé denominadas según la línea de ascendencia vinculada a las "naciones" que formaron los esclavizados y las esclavizadas llegadas de diversas regiones de África. Así, se pueden encontrar candomblé nagô, ewe, jejé, mina, queto, oyo, ijexá, angola, congo, etc. Estas formaciones generaron intercambios entre ellas y establecieron nuevas prácticas rituales, también influenciadas por las condiciones del nuevo contexto social, lo que se traduce en semejanzas entre las estructuras rituales de una y otra nación, pero también en diferencias que pueden verse reflejadas en la manera de tocar el tambor (con las manos o con baquetas), la música, las ropas litúrgicas y el idioma de cánticos y nombres de las divinidades.

En el caso de este artículo, me enfocaré en las prácticas rituales vinculadas a la ascendencia yoruba, en las que la ejecución de los tambores está a cargo de los ogãs, puesto jerárquico exclusivamente masculino del que las mujeres quedan relegadas por un tabú sagrado que involucra la menstruación. De esta manera, a partir de una investigación que todavía está en curso, basada en trabajo etnográfico en distintos terreiros de Salvador de Bahía, a partir de la observación participante, la recolección de testimonios y entrevistas realizadas a diversos miembros y allegados de los candomblés visitados, se propone un breve recorrido por la presencia y funciones que ocupan las mujeres dentro del terreiro, las implicaciones socio-culturales que tiene la menstruación dentro de esta comunidad y la prohibición sobre las mujeres de tocar los ilus consagrados en las ceremonias rituales. 


\section{La presencia femenina en el terreiro}

Un aspecto en el que muchos investigadores e investigadoras hicieron énfasis, como Bastide (1969), es la importante presencia de mujeres en las comunidades candomblecistas. Este autor sostiene que existe una preeminencia de las mujeres tanto entre los liderazgos del candomblé nagô, como entre los fieles practicantes. En esa misma dirección, Silva Bastos (2009) plantea que "en las religiones afro-brasileñas, particularmente, el sexo femenino parece ocupar una posición de mayor destaque en comparación a las otras religiones"1 (p. 156). Pierre Verger (1985) agrega que existe una cantidad mayoritaria de mujeres liderando los candomblés de ascendencia yoruba, mientras que, por ejemplo, en los candomblés bantos prevalecerían los hombres. Esto podría estar ligado a la formación de hermandades católicas de la colonia que aglutinaban hombres y mujeres africanas por separado.

Una de las hermandades de mujeres más importante surgió de la Iglesia de Barroquinha, la Irmandade da Boa Morte, creada en el siglo XIX por un grupo de mujeres negras de ascendencia yoruba, en la cual, según Livia Baeta da Silva (2005), tenían total libertad para decidir, organizar y reinar las festividades. Más tarde, la Irmandade da Boa Morte se trasladó a Cachoeira, pero antes, como describen Pierre Verger (1985) y Baeta da Silva (2005), dejó como legado el primer terreiro de candomblé de Salvador de Bahía, lya Omi Ayá Intilá, inicialmente instalado en las inmediaciones de la Iglesia de Barroquinha. Según el Mestre luri Passos de Barros (2017), de él se desprenden los terreiros llê lyá Nassô Oká, también conocido como Casa Branca o Engenho Velho, en Vasco da Gama, Ilê Axé Opô Afonjá, en São Gonçalo do Retiro, e Ilê Omim lyá Massê, en Federação, más conocido como Gantois. Estos terreiros son considerados los más antiguos de Salvador de Bahía y se caracterizan por mantener una línea de lideresas exclusivamente femenina.

La hipótesis que plantea Verger (1985) a este respecto es que "la influencia de las mujeres en el candomblé se hacía sentir más que la de los hombres porque ellas eran más numerosas en poder comprar su libertad”2 (p.277). Ya en la sociedad nagô-yorubana, si bien un hombre podía casarse hasta con cuatro mujeres, la mujer gozaba de cierta independencia que se fundamentaba en su capacidad para el comercio. En Brasil, una vez emancipadas, disponían del dinero necesario para la práctica de sus cultos africanos (Verger, 1985).

\footnotetext{
${ }^{1}$ En original: "[n]as religiões afro-brasileiras, particularmente, o sexo feminino parece ocupar uma posição de maior destaque em comparação às outras religiões".

2 En original: "[a] influência das mulheres no candomblé fazia sentir-se mais do que a dos homens porque elas eram mais numerosas a poder comprar a sua liberdade".
} 
En esta línea, Rita Segato (2003) también señala el desarrollo autónomo y económico de las mujeres africanas que conseguían liberarse en Brasil y plantea que los hombres quedaron en una situación de desventaja en la cual los vínculos de la familia tradicional occidental patriarcal difícilmente pudieron establecerse. Sin dinero, sin estatus social, los hombres no tenían como sostener la familia, y muchos debían movilizarse de un lugar a otro para conseguir trabajo. De esta manera, Segato (2003) sostiene que "[e]l modelo del pater familias blanco también quedó fuera de sus posibilidades", como consecuencia, hubo una transformación en los patrones de comportamiento y una modificación sobre "las concepciones de la actuación de hombres y mujeres en el plano cultural y las expectativas sobre su papel en el plano social” (p. 210).

Asimismo, Segato (2003) informa, sobre el grupo que estudió, los xangôs de Recife, pero aplicable en general, que el determinismo biológico de los sexos para la definición de roles y jerarquías propias de occidente no funciona dentro de estos grupos, y enumera una serie de elementos que justifica esta afirmación, entre los cuales está "la práctica de atribuir "santos hombres" y "santos mujeres" a hombres y mujeres, indistintamente, como tipo de personalidad", el tratamiento de roles femeninos y masculinos en los mitos de los orixás, y la importancia asignada a la "familia de santo" y "a la adopción de "hijos de crianza", en desmedro del parentesco basado en lazos de sangre" (p. 181).

Justamente a esto se refiere Oyèroké Oyěwùmi (2017) al poner en evidencia la "transformación epistemológica derivada de la imposición de las categorías occidentales de género en el debate sobre Yorùbá" ( $p$. 15), entendiendo que éstas tienen su fundamento en la "lógica occidental biologicista", la ideología del determinismo biológico. Según la autora, esta lógica se impone como epistemología colonial en tanto que "[e]n la sociedad Yorùbá precolonial, el tipo de cuerpo no era la base de la jerarquía social: la posición social de machos y hembras no dependía de su distinción anatómica" (Oyěwùmi, 2017, p. 19), y, por lo tanto, no había supremacía de un género sobre otro. En términos de Silva Bastos (2009), "en la concepción del grupo estudiado, el género no era innato. No predomina entre ellos el pensamiento esencialista biológico. Hay una comprensión del género como algo influenciado socio-culturalmente"3 (p. 161). Esto se ve reflejado en la indiferencia hacia las instituciones occidentales que sostienen la concepción biologicista y la jerarquía de género a la que se hizo referencia previamente.

A este respecto, Segato (2003) sostiene que tanto en el plano psicológico, como en el religioso y el social, la diferencia biológica no es definitoria, sin embargo, sí lo es en el aspecto ritual. Para cualquier ceremonia, la música de los tambores y los cánticos son esenciales, los atabaques o ilus son "quienes hablan el lenguaje de las divinidades". Como

\footnotetext{
${ }^{3}$ En original: “...na concepção do grupo estudado, o gênero não é inato. Não predomina entre eles o pensamento essencialista biológico. Há a compreensão de gênero como algo influenciado sócio-culturalmente"
} 
expresó la Mãe Claudia de Oxalá (entrevista, febrero de 2019), lideresa del terreiro llê Asé Baba Alá Ayê de Castelo Branco, los tambores llaman a los orixás, permiten el trance y la comunicación entre fieles y dioses. Estos atabaques consagrados son tocados de manera exclusiva por los ogãs u ogan, tradicionalmente asociados a hombres protectores del terreiro, como estipula Santos (2009), desde las épocas en las que los candomblés eran perseguidos por la policía y los medios de comunicación. Los ogãs, también llamados alagbes o alabês (referido al aspecto musical específico), ocupan un puesto honorario en el terreiro, son los que pueden tocar los tambores consagrados y llevar a cabo las funciones de sacrificio animal, además de que tienen la particularidad de no poder ser "montados" o "virar" (no pueden caer en trance), al igual que las ékédi o ekedys (mujeres cuidadoras de los hijos de santo que tampoco caen en trance, pero no tocan los tambores).

Edmar Ferreira Santos (2009), en un extenso trabajo sobre el Recôncavo bahiano, habla de los Ogãs y sus funciones políticas, reflejadas en la prensa de principios de siglo $X X$. Los destaca como figura preeminente de los candomblés que aparecía a veces en las noticias como "un dios que es adorado por sus seguidores, otras veces, aunque en el mismo sentido, como una especie de origen de las "farras negras", confundidos con los pais-de-santo o corrompiendo mujeres"4 (p. 116). Asimismo, el autor resalta la presencia de nombres de personajes importantes de la sociedad local, "responsables por proporcionar licencias para tocar candomblés, o individuos clasificados como "embajadores" de los terreiros en las relaciones con las autoridades policiales"5 (Ferreira Santos, 2009, p.116). En este sentido, los ogãs asumían responsabilidades vinculadas a la resolución de problemas externos a la comunidad religiosa, convirtiéndose en figuras públicas. Ferreira Santos (2009) explica a este respecto que "se tornó un lugar común la percepción de su función como el ejercicio de un cargo de naturaleza honorífica, del cual madres y padres de santo se valieron, escogiendo blancos o personas de mayor poder adquisitivo para ayudarlos y protegerlos"6 (p. 117), olvidando muchas veces las atribuciones rituales, los privilegios y las obligaciones que tienen en el interior del candomblé.

Sin embargo, Rocha (2018), en línea con lo que plantea Oyèroké Oyěwùmi (2017), repasa los fundamentos del mito difundido sobre la creación del tambor ritual y el tabú que

\footnotetext{
${ }^{4}$ En original: "um deus que é adorado por seus seguidores, outras vezes, embora no mesmo sentido, como uma espécie de origem das "farras negras", confundidos com os pais-de-santo ou corrompendo mulheres".

${ }^{5}$ En original: "responsáveis inclusive por fornecerem licenças para se tocar candomblés, ou indivíduos classificados como "embaixadores" dos terreiros nas relações com as autoridades policiais".

${ }^{6}$ En original: "tornou-se lugar comum a percepção de sua função como o exercício de um cargo de natureza honorífica, do qual mães e pais-de-santo se valeram, escolhendo brancos ou pessoas de maior poder aquisitivo para lhes ajudar e proteger".
} 
sostiene esta separación de mujeres y tambores, básicamente la menstruación de la mujer. Luego de un mapeo de otros mitos que contradicen el que fue divulgado, y la mención de diversas mujeres que han ocupado ese espacio ritual, Rocha (2018) se pregunta si

Alagbe será un título honorífico exclusivamente masculino desde el principio, como quieren las comunidades afro-religiosas candomblecistas en el contexto bahiano, o será un título unisex, que en algún tiempo, cuando todavía territorializado en África, el culto sagrado permitía el tránsito libre de mujeres también en este espacio simbólico ${ }^{7}$ (p. 7).

\section{El tabú de la menstruación}

La menstruación de la mujer ha sido objeto de distintas interpretaciones y significados múltiples a lo largo de la historia de la humanidad. Es motivo de diversas creencias y costumbres que varían según la comunidad, lo que, como plantea Cecilia Sardenberg (1994), significa que no se trata de un simple hecho biológico, sino que posee una carga simbólica construida social y culturalmente en cada sociedad. Esta autora presenta más de un ejemplo de distintas comunidades del mundo sobre actividades o prácticas que las mujeres menstruantes tienen restringidas, tanto en el ámbito profano como en el ámbito de lo sagrado, e introduce la categoría de "órdenes práctico-simbólicas de la menstruación" para reflexionar al respecto:

... esos órdenes obedecen a una lógica interna que se incorpora y/o abarca elementos de otros sistemas o sub-sistemas semejantes, como por ejemplo los referentes a las ideologías de reproducción y parentesco, a las prácticas alimentarias, a las concepciones sobre el cuerpo y la enfermedad, al ejercicio de la sexualidad, etc. Eso significa que ellos se constituyen como una clase de fenómenos que no pueden ser analizados aisladamente ${ }^{8}$ (Sardenberg, 1994, p. 334).

De esta manera, la menstruación como fenómeno biológico propio de las mujeres, se constituye primero que nada en un factor de demarcación de diferencias, pero no sólo entre hombres y mujeres, sino también entre mujeres de diferentes edades en torno a la menopausia. Sardenberg (1994) expresa que "las sociedades estudiadas toman a la menstruación y a la menopausia como marcos para la identificación y clasificación de

\footnotetext{
7 En original: "Alagbe será um título honorífico exclusivamente masculino desde o princípio, como querem as comunidades afro-religiosas candomblecistas no contexto baiano, ou será um título unissex, que em algum tempo, quando ainda territorializado em África, o culto sagrado permitia o trânsito livre de mulheres neste espaço simbólico também?".

${ }^{8}$ En original: "...essas ordens obedecem a uma lógica interna que se incorpora e/ou perpassa elementos de outros sistemas ou sub-sistemas semelhantes, como por exemplo os referentes às ideologias da reprodução e parentesco, às práticas alimentares, às concepções sobre 0 corpo e doença, ao exercício da sexualidade etc. Isso significa que elas se constituem como uma classe de fenômenos que não podem ser analisados isoladamente".
} 
mujeres y para la diferenciación de papeles, actividades y comportamientos correspondientes a tal clasificación"9 (p. 336). Esta clasificación permite en ciertas comunidades hablar de "mujeres menstruantes" y "personas no-menstruantes", como si la menopausia implicara un escape a la categoría de mujer para pasar a ser persona. De esta manera, Sardenberg (1994) explica que:

En varias sociedades, esas creencias y costumbres se traducen en formas de legitimar la exclusión de la mujer de la participación en determinadas actividades, principalmente de aquellas de carácter dicho público. Así, supuestos poderes de la sangre menstrual acaban por traducirse en un no poder para la mujer menstruada: no puede comer determinados alimentos, no puede participar de determinados rituales, no puede disfrutar del convivio social, y así por delante. En muchas sociedades, entonces, menstruar significa exclusión y eso, ciertamente, tiene consecuencias en lo que hace a la manera de las mujeres de vivenciar la menstruación. (...) Pero hay que tener en cuenta que los significados atribuidos a la menstruación varían no sólo entre una sociedad y otra como también internamente, o sea, entre diferentes clases sociales, grupos étnicos, generaciones o mismo entre hombres y mujeres de esos segmentos ${ }^{10}$. [negrita original del texto] (pp. 335-336).

La sangre en general es muy importante en las prácticas rituales del candomblé, funciona como "símbolo-llave" como plantea Barros Gama (2009), siendo central el sacrificio animal para establecer el vínculo de los y las iniciadas con su orixá, para fortalecer el axé de la cabeza, de los objetos sagrados - incluidos los tambores consagrados - y para ofrendar a las divinidades. Pero también puede estar asociada, cuando no es requerida por los orixás, a enfermedades e impurezas. La sangre menstrual en particular tiene una asociación positiva, está vinculada a la fertilidad. Como señala Barros Gama (2009) ${ }^{11}$, existen mitos que explican esta relación. Así también existen otras narraciones que se refieren a la menstruación como tabú ${ }^{12}$. De esta manera, "la sangre de "las reglas" que tiene el poder de generar los descendientes, pero que también desprende

\footnotetext{
9 En original: "as sociedades estudadas tomam a menarca e a menopausa como marcos para a identificação e classificação de mulheres e para a diferenciação de papéis, atividades e comportamentos correspondentes a tal classificação".

10 En original: "Em várias sociedades, essas crenças e costumes se traduzem em formas de legitimar a exclusão da mulher da participação em determinadas atividades, principalmente daquelas de caráter dito público. Assim, supostos poderes do sangue menstrual acabam por se traduzir em um não poder para a mulher menstruada: não poder comer determinados alimentos, não poder participar de determinados rituais, não poder desfrutar do convívio social, e assim por diante. Em muitas sociedades, portanto, menstruar significa exclusão e isso, certamente, tem consequências no que tange à maneira de as mulheres vivenciarem a menstruação. (...) Mas há de se levar em conta que os significados atribuídos à menstruação variam não apenas entre uma sociedade e outra como também internamente, ou seja, entre diferentes classes sociais, grupos étnicos, gerações ou mesmo entre homens e mulheres desses segmentos".

11 Ver "Obatalá fere acidentalmente sua esposa lemu" (Prandi, 2001, p. 508).

12 Ver "Oxum transforma sangue menstrual em penas de papagaio" (Prandi, 2001, p. 329).
} 
el axê"13 (Barros Gama, 2009, p.115), posee una característica doble que se refleja, por un lado, en las ofrendas, y por el otro, en las prohibiciones.

Cuando una mujer está menstruando, se considera que está en un estado de debilidad y por lo tanto no sólo absorbe la energía de objetos sagrados y ofrendas, sino que también se encuentra imposibilitada de proceder en los rituales. Como describe Barros Gama (2009):

El cuerpo necesita estar fuerte para la experimentación de lo sobrenatural y un cuerpo fuerte consiste en un axé mantenido e intensificado, condición ésta antagónica al estado menstrual (...) durante el sangramiento, está vetada la participación femenina en la preparación de los alimentos ofrecidos a los santos, su presencia en el peji, en el xirê siendo igualmente impedida su permanencia en el salón en días de obligaciones y toques ${ }^{14}$ (p. 79).

En este sentido, Bastide (1961) relata que las mujeres menstruantes "no deben ni siquiera asistir a la fiesta puesto que las divinidades tienen terror al sangre catamenial; si una de ellas osa desobedecer, inmediatamente los tambores lo reconocen, pues su simple presencia perturba el toque musical"15 (p. 29). En otra parte de su trabajo agrega que "la yauô [hija de santo iniciada] no podrá, tampoco, ser poseída mientras esté en ese estado $y$, si alguna mujer menstruada penetra en el santuario en el transcurrir de la fiesta, inmediatamente los tambores desafinan"16, y, por último, "las iniciadas no llegan al grado supremo de ialorixá sino cuando, según la expresión popular, "se tornaron hombres", esto es, después de la menopausia"17 (Bastide, 1961, p. 186).

Bastide (1961) sostiene que no es posible consagrarse lideresa de un terreiro sin haber entrado en la menopausia, "tornarse hombre" en sus palabras, lo que en realidad tiene cierto sentido cuando se observa el panorama general de las mujeres mayores que están en los puestos superiores de la jerarquía. Sin embargo, hay casos en que los orixás han escogido lideresas que no han llegado aún a ese momento de su vida, por ejemplo, el

\footnotetext{
${ }^{13}$ En original: "[o] sangue "das regras" que tem o poder de gerar os descendentes, mas que também desprende o axé"

${ }^{14}$ En original: "O corpo necessita estar forte para a experimentação do sobrenatural e um corpo forte consiste num axé mantido e intensificado, condição esta antagônica ao estado menstrual (...) durante o sangramento, é vetada a participação feminina no preparo dos alimentos ofertados aos santos, sua presença no peji, no xirê, sendo igualmente impedida sua permanência no salão em dias de obrigação e toques".

15 En original: "não devem nem mesmo assistir à festa pois as divindades têm horror ao sangue catamenial; se uma delas ousa desobedecer, imediatamente os tambores o reconhecem, pois sua simples presença perturba o toque musical".

${ }^{16}$ En original: "a yauô não poderá, também, ser possuída enquanto estiver neste estado e, se alguma mulher menstruada penetra no santuário no decorrer da festa, imediatamente os tambores desafinam".

17 En original: "as iniciadas não chegam ao grau supremo do ialorixá senão quando, segundo a expressão popular, "tornaram-se homens", isto é, depois da menopausa".
} 
caso de la ya mencionada Mãe Claudia de Oxalá, que fue escogida de muy joven, y abrió su terreiro cuando tenía alrededor de 30 años.

\section{Los atabaques del candomblé}

Respecto a los tambores y sus ejecutantes, en el terreiro de Gantois existe una presencia muy importante de percusionistas mujeres, no dentro del contexto sagrado, pero sí percusionistas que fueron aprendiendo en la cotidianeidad del candomblé. La famosa Mãe Menininha (1894-1986), bisnieta de la fundadora del terreiro, supo tener gran habilidad para el toque de los atabaques y otros instrumentos, y su nieta, Mônica Millet, es una reconocida percusionista profesional, fundadora de las Mestras do Saber, un grupo de percusión exclusivo de mujeres. En este terreiro se desarrolla el proyecto "Rum Alagbê", a cargo del alagbê de la casa, Mestre luri Passos de Barros, que se dedica a enseñar los ritmos sagrados a niños y niñas, hombres y mujeres, interesados en la percusión, en el candomblé y en la música ancestral en general. A este respecto, el Mestre luri expresa:

Sobre la enseñanza y el aprendizaje de los ritmos de candomblé para las mujeres, las dudas son muchas, entretanto todavía estamos por descubrir cuáles serán las consecuencias que eso traerá para la religión del candomblé, pero, por el momento, el proyecto Rum Alagbê viene cubriendo una laguna en relación a la enseñanza de la cultura negra en Brasil.

No sabemos todavía cuáles son las expectativas del pueblo del candomblé sobre la enseñanza de los atabaques para mujeres, mientras tanto, por esa enseñanza ser dentro del terreiro de Gantois, uno de los mayores y más antiguos terreiros de Salvador, ese hecho tiene un peso muy grande ${ }^{18}$ (Passos de Barros, 2017, p. 104).

He tenido la posibilidad de conocer mujeres percusionistas bahianas, algunas miembros de las Mestras do Saber, que a su vez se consideran mujeres de axé, tienen su fe religiosa en el candomblé y las divinidades yoruba, pero la experiencia de estar restringidas por estos tabús de la menstruación fue un impedimento para considerar una iniciación como hijas de santo de un terreiro. Por lo tanto, no se trata de una simple cuestión de fe, la menstruación se define como un factor que establece un vínculo entre lo biológico y lo cultural, que interactúa constantemente con las construcciones simbólicas de una sociedad y de la identidad individual de una mujer y termina colaborando con la justificación de un status quo vigente. A este respecto, Sardenberg (1994) sostiene que se

\footnotetext{
${ }^{18}$ En original: "Sobre o ensino e aprendizagem dos ritmos do candomblé para as mulheres, as dúvidas são muitas, entretanto ainda estamos por descobrir quais consequências isso irá trazer para a religião do candomblé, mas, no momento, o projeto Rum Alagbê vem cumprindo uma lacuna em relação ao ensino da cultura negra no Brasil".

"Não sabemos ainda quais são as expectativas do povo do candomblé sobre o ensino dos atabaques para mulheres, no entanto, por esse ensino ser dentro do terreiro do Gantois, um dos maiores e mais antigos terreiros de Salvador, esse fato tem um peso muito grande"
} 
trata de una relación multilateral entre lo biológico y lo cultural, "una relación dialéctica, que es mediada por otros elementos y aspectos de la cultura y estructura social, específicos de cada sociedad"19, y, por esta razón, las representaciones sobre la menstruación de una determinada comunidad "se presentan como un recorte analítico que nos permite vislumbrar como la relación entre biología y cultura se configura en contextos históricosociales específicos"20 (p. 344).

En este sentido, una de las dificultades que se presenta a la hora de aproximarse a la cuestión de género en el candomblé afro-bahiano parte justamente de estas diferencias en su cosmovisión respecto a la occidental hegemónica y de las complejidades propias del contexto de lo sagrado de esta comunidad específica. Así, se puede pensar que, en esa inserción forzada de las mujeres y hombres africanos en la América Colonial, se introdujeron prácticas originarias del continente trasatlántico, pero también se produjeron variaciones. De esta forma, Rocha (2018) plantea:

El título honorífico de alagbe hoy, en el contexto candomblecista es designado exclusivamente al ente masculino, por este ser considerado puro a punto de consagrarse a la mística percusiva sagrada. Respaldada por el tabú de la menstruación e instituido casi que unánimemente en las casas de candomblé en Brasil, la interdicción de la mujer al tambor sagrado refuerza estereotipos de género conflictivos con las discusiones de su tiempo ${ }^{21}$ (p. 8).

Los mitos difundidos funcionan como un cúmulo específico de saberes que son "incuestionables" para ciertos practicantes del candomblé afro-bahiano. Uno de los ogãs entrevistados, perteneciente a un terreiro muy tradicional de Salvador, explicó que las mujeres no pueden tocar el tambor por la menstruación y que no es una cuestión de machismo, sino que es una imposición divina, "los dioses no quieren mujer cerca del tambor por causa de la vida que expulsan cada mes"22.

En este sentido, el Mestre luri hace referencia a la trascendencia que tienen las mujeres del terreiro en el aprendizaje de los ogãs, "dado que ellas, al introducir los matices debidos, orientan a los músicos con las marcaciones que los atabaques deben hacer cuando los orixás están bailando en el salón, haciendo que los Ogãs absorban esa cultura

19 En original: "uma relação dialética, que é mediada por elementos e aspectos outros da cultura e estrutura social, específicos a cada sociedade"

20 En original: "se apresenta como um recorte analítico que permite vislumbrarmos como a relação entre biologia e cultura se configura em contextos histórico-sociais específicos"

${ }^{21}$ En original: "O título honorífico de alagbe hoje, no contexto candomblecista é designado exclusivamente ao ente masculino, por este ser considerado puro a ponto de se consagrar à mística percussiva sagrada. Respaldada pelo tabu do "bajé" [menstruación] e instituído quase que unanimemente nas casas de candomblé no Brasil, a interdição da mulher ao tambor sagrado reforça estereótipos de gênero conflitivos com as discussões do seu tempo"

22 En original: "os deuses não querem mulher perto do tambor por causa da vida que expulsam cada mês". Testimonio recogido por la autora de un Ogã de un terreiro muy tradicional de Salvador, que pidió que se resguardara el nombre. 
y sensibilidad acústica"23 (Passos de Barros, 2017, p. 103). A su vez, reivindica la importancia de continuar enseñándoles los toques sagrados "simplemente debido al hecho de que la mujer está contribuyendo con la relevancia que le cabe (dominando) el conocimiento de los ritmos, cantos y danzas sagradas, sin hablar de otros fundamentos del candomblé"24 (Passos de Barros, 2017, p. 106).

Sin embargo, este alagbê sostiene, junto a los testimonios de ogãs que presenta en su trabajo, que en el contexto sagrado esta dimensión de los atabaques es exclusivamente masculina, las mujeres no van a tocar en el terreiro, y que los tutores de los atabaques serán siempre los maestros "los Alagbês, Xikarongomas y Huntós. Ellos fueron escogidos por los Orixás, Voduns e Inkices, para ejercer la función de tocar los atabaques dentro del candomblé que practicamos en Brasil. Son ellos los responsables de perpetuar esa linda cultura percusiva"25 (Passos de Barros, 2017, pp. 115-116).

Retomando las propuestas de Segato, en "Género, y Colonialidad: en busca de claves de lectura y de un vocabulario estratégico descolonial” (2011) se plantea la categoría de "pluralismo histórico", que implica que "[l]os sujetos colectivos de esa pluralidad de historias son los pueblos, con autonomía deliberativa para producir su proceso histórico, aun cuando en contacto, como siempre ha sido, con la experiencia y los procesos de otros pueblos" [cursiva original del texto] (2011, s/p). La autora introduce una consideración respecto a la aproximación de género en sociedades previas a la intrusión de la colonización occidental, "la existencia de nomenclaturas de género en las sociedades tribales y afro-americanas", es decir, que había "en las sociedades indígenas y afroamericanas una organización patriarcal, aunque diferente a la del género occidental y que podría ser descripta como un patriarcado de baja intensidad" (2011, s/p). De esta forma, Segato cuestiona de alguna manera la tesis de Oyèroké Oyěwùmi (2017) de la noexistencia de una diferenciación entre géneros en el contexto africano pre-colonial, aunque enfatiza que no se da un patriarcado igual al modelo occidental.

En esta línea, la autora señala que "los orixás, en su primera subdivisión en masculinos y femeninos, constituyen estereotipos de género" y que incluso "[d]entro de cada categoría se habla asimismo de grados relativos de femineidad y masculinidad" (Segato, 2003, p.185). En las asignaciones de orixás para los hijos e hijas de santo, el culto pone "al alcance de sus miembros un sistema de clasificación de las personalidades

${ }^{23}$ En original: "dado que elas, ao introduzirem as nuances devidas, orientam os músicos com as marcações que os atabaques devem fazer quando os orixás estiverem dançando no salão, fazendo com que os Ogãs absorvam essa cultura e sensibilidade acústica"

24 En original: "[s]implesmente devido ao fato que a mulher está contribuindo com a relevância que the cabe (dominando) o conhecimento dos ritmos, cantos e danças sagradas, sem falar dos outros fundamentos do candomblé"

${ }^{25}$ En original: "os Alagbês, Xikarongomas e Huntós. Eles foram escolhidos pelos Orixás, Voduns e Inkices para exercer a função de tocar os atabaques dentro do candomblé que praticamos no Brasil. São eles os responsáveis por perpetuar essa linda cultura percussiva" 
como predominantemente femeninas o masculinas, en el cual se distingue con claridad este aspecto psicológico de otros componentes de la identidad de género de la persona" (Segato, 2003, p. 186).

Según las investigaciones realizadas por Segato (2003) con los xangôs de Recife, se encuentra que:

[u]na postura de carácter no esencialista impregna tres grupos de nociones de la visión del mundo del xangô: 1) la negación del imperativo del fundamento natural (...) como base de vínculos caracterizados por la solidaridad mutua y organizados de acuerdo con el modelo de la familia; 2) la negación del fundamento "natural" de las categorías de género, vale decir, la descomposición del sistema sexo/género en sus partes constituyentes, que no se consideran interdependientes, y 3) la negación del fundamento "natural" de la relación materna, esto es, la descomposición de la equivalencia entre madre progenitora y madre de crianza (p. 218).

Estas conclusiones son compartidas por Cordovil (2016), quien aporta que en el marco de un candomblé hay dos tipos de personas definidas por si pueden o no caer en trance, ella los nombra como rodantes y no rodantes. Las y los rodantes, mujeres y hombres que pueden caer en trance, es decir, recibir al orixá, no presentan distinciones de género en el marco ritual del terreiro. Sin embargo, se aprecian grandes diferencias entre los y las no rodantes, las mujeres que ocupan el cargo de ekédis o ekedys y los hombres que ocupan el cargo de ogãs. Las ekédis son asistentes de los fieles que entran en trance, se encargan de vestirlos y cuidar de sus ropas y accesorios litúrgicos, colaboran con la preparación de las comidas para las ofrendas y con la organización general de la ceremonia. Los ogãs, como ya se mencionó, se encargan de los sacrificios animales y de la ejecución de los tambores durante el ritual. En función a esta división de trabajo entre los géneros, Cordovil (2016) sostiene que se puede percibir que "las mujeres ocupan muchos papeles simbólicamente relacionados a la cocina, al espacio doméstico, al cuidado y a la nutrición" ${ }^{26}$, mientras que, las fiestas públicas, momento en el que el terreiro se abre para recibir personas externas, "los ogãs ocupan un papel importante, pues son responsables de la música ritual"27 (p. 128).

Aparece aquí otra referencia a una distinción de género similar a la del orden patriarcal de occidente, el ámbito privado estipulado para la mujer y el ámbito público perteneciente a los hombres. La faceta ritual del candomblé abre algunas preguntas sobre la dimensión de género, a lo que cabría agregar, aunque excede este trabajo, el hecho de que todos los sacerdocios externos al terreiro, los babalaô (encargados del culto a Ifá y el arte de la adivinación), los babalossain (ligados a Ossain y las hierbas y hojas medicinales)

\footnotetext{
${ }^{26}$ En original: "que as mulheres ocupam muitos papéis simbolicamente relacionados à cozinha, ao espaço doméstico, ao cuidado e à nutrição".

${ }^{27}$ En original: "os ogãs ocupam papel importante, pois são responsáveis pela música ritual".
} 
y los babaogê (sacerdotes del culto de los antepasados y los muertos, eguns), también son potestad exclusiva de los hombres.

\section{Consideraciones Finales}

En términos generales, la estructuración de prácticas de ascendencia yoruba en el candomblé como religión desarrollada en Brasil, permitió un espacio en el que se pudo conservar y reproducir el legado ancestral de las culturas africanas, con las variantes y negociaciones que requirieron tanto en el contacto con grupos de diferentes regiones de África, como en las condiciones sociales y marginales de la sociedad colonial y "poscolonial" brasileña. Como sostienen Minz y Price (2012), "[d]esde el principio, el compromiso con una cultura de africano-americanos nueva, en un lugar dado, incluyó una expectativa de dinamismo, cambio, elaboración y creatividad continuo" (p.91). El candomblé como práctica religiosa fue construida en Brasil con la suma de elementos que africanos y africanas de diversas etnias y cosmovisiones fueron aportando, y en interacción con el colono europeo y las comunidades indígenas que ya habitaban el lugar. De esta manera, viabilizó la organización de una memoria colectiva a través de un continuum entre las culturas africanas y las afrodescendientes brasileñas cuyo fundamento, como plantea Hodge Limonta (2009), son los 256 odus, o "caminos" de la cosmovisión yoruba, y las historias orales que se conservaron en las nuevas formas religiosas. Parte de la tradición oral africana es resguardada en los terreiros.

Ahora bien, esta tradición plantea algunos debates respecto a la vivencia religiosa y los privilegios históricos de ciertos grupos. La prohibición que determina que las mujeres no pueden tocar los tambores consagrados existe, pero las razones aún no son claras. En la investigación que todavía está en curso, las respuestas de los y las practicantes consultadas son variadas, pero coinciden en que el problema central está en la menstruación. Por un lado, algunos/as mencionaron que el tabú se establece porque la sangre menstrual sería una vida potencial que se pierde, por lo tanto, está más vinculada a la muerte y a los orixás no les gusta estar en contacto con ella. Por otro lado, la Mãe Claudia de Oxalá (entrevista, febrero de 2019) explicó que las mujeres menstruantes absorben la energía y la envían al útero en este proceso que podría crear vida, por lo que atraerían toda la energía de los objetos sagrados destinada para los orixás, en línea con los testimonios de los investigadores y las investigadoras presentados anteriormente.

Sin embargo, las otras tareas que cumplen las mujeres dentro del terreiro, como el cuidado de los hijos de santo en trance, la cocina de los platos de ofrendas para las divinidades, o la supervisión y el aseo de la casa y de los pegi (altares) de las divinidades, deben dejar de cumplirlas los días que están menstruando, manteniéndose alejadas de los espacios sagrados, pero el resto de los días continúan con sus tareas. ¿Por qué en el caso 
de los tambores no se replica este esquema? ¿Por qué las mujeres no pueden tocar los tambores el resto de los días del mes que no menstrúan? $\mathrm{Y}$, en esta línea de cuestionamientos, aunque excede la investigación que está en curso, también se podría preguntar ¿qué sucede con las personas transexuales?

Por supuesto, estos interrogantes forman parte de un debate que no está saldado, pero vale la pena plantearlo, sobre todo porque a veces a través de la defensa de una tradición se acaban replicando, sin intención, esquemas de exclusión y/u opresión. Paul Gilroy (2014) lo expone de manera muy concreta en referencia a las producciones culturales del Atlántico Negro en general:

La idea, algunas veces antigua y siempre antimoderna, de disponer de un acceso a la tradición y dominarla, se ha vuelto esencial para los mecanismos disciplinarios que los actuales tradicionalistas duros buscan aplicar sobre diversos procesos de la producción cultural negra. La tradición proporciona el vínculo crítico entre los atributos locales de las formas y estilos culturales y sus orígenes africanos. (...) la tradición se vuelve el medio para demostrar la contigüidad de escogidos fenómenos contemporáneos con un pasado africano que les dio forma pero al que ya no reconocen y al que solamente se parecen ligeramente. África se conserva como una especial medida de su autenticidad (p. 237).

Los guardianes de la tradición están dispuestos a hacer ciertas negociaciones para la prevalencia de las prácticas religiosas, por ejemplo, los períodos de reclusión que antes se exigían para ser iniciado en el candomblé eran muy prolongados, en cambio, hoy en día, es casi imposible sostenerlo con las exigencias de trabajo y manutención de la vida moderna. Pero a la hora de replantear la identidad cultural que protege esa tradición frente a las reivindicaciones que están en proceso en el mundo de hoy, hay otros elementos que no entran en la discusión.

En este sentido, se puede observar cómo, además de los condicionamientos culturales y sociales que implicó la instauración y reproducción del candomblé en Salvador de Bahía, existió una dimensión de la política identitaria, en el fortalecimiento de la comunidad candomblecista, que quedó soslayada. Como sostiene Crenshaw (2012), "[e]l problema con las políticas identitarias no es que no vayan más allá de la diferencia, como afirman algunas críticas, sino lo contrario - que frecuentemente reducimos o ignoramos las diferencias intra - grupales" (p. 88). Esta autora explica justamente que "la identidad se conforma en diferentes terrenos, ligados a la construcción del mundo social" (2012, p.90). El candomblé es parte de la identidad cultural de los y las afrobrasileñas y otros adeptos, y como menciona Stuart Hall (2010), esta identidad es una producción que se construye en diálogo con el pasado, a través de la memoria, la narrativa y el mito. "Las identidades culturales son puntos de identificación, los puntos inestables de identificación o sutura, que son hechos dentro de los discursos de la historia y de la cultura. No son una esencia sino un posicionamiento" (p. 352). 
De esta manera, la institución de los ogãs, esos hombres con gran prestigio social y religioso, protectores del terreiro y ejecutores de los tambores sagrados, que además son importantes músicos en la escena artística pública de Bahía, reproduce una fórmula ya conocida en la sociedad occidental en general, la reclusión de las mujeres a los espacios privados, al trabajo doméstico y de cuidados cuando no pueden caer en trance, y la exclusión de aquellas mujeres en el momento de su menstruación, como también se registra en la historia de la tradición judeo-cristiana occidental (Barros Gama, 2009).

En este punto, todavía quedan preguntas a realizarse frente a los desafíos que plantean las demandas de las luchas actuales de las mujeres, en particular de las mujeres afrodescendientes, para lo que es interesante recurrir al concepto de interseccionalidad. Mara Viveros Vigoya (2016) explica que los análisis interseccionales, vinculados principalmente con los feminismos de las mujeres de color, revelan elementos que se ignoran a partir de las categorizaciones estándares del discurso eurocéntrico, poniendo de manifiesto dos situaciones: "la multiplicidad de experiencias de sexismo vividas por distintas mujeres, y (...) la existencia de posiciones sociales que no padecen ni la marginación ni la discriminación, porque encarnan la norma misma, como la masculinidad, la heteronormatividad o la blanquitud" (p. 8). En este sentido, María Lugones (2010) aporta que '[e]n la intersección entre 'mujer' y 'negro' hay una ausencia donde debería estar la mujer negra precisamente porque ni 'mujer' ni 'negro' la incluyen. La intersección nos muestra un vacío", y, por lo tanto, "[s]olo al percibir género y raza como entretramados o fusionados indisolublemente podemos realmente ver a las mujeres de color" (p. 82).

En Nigeria, en la región en la que se originó el culto de ljexá presente en Brasil, el ritual destinado a la diosa de las aguas, el amor y la fertilidad, Oxum, es exclusivo de mujeres y son ellas las que tienen permitido tocar para este ritual. Una sacerdotisa argentina, iniciada en el continente africano, Judith Ti Yemoja Eégúnfemi, expresó en una charla que las mujeres no tienen esa restricción respecto de los tambores en ese contexto. Entonces, se puede pensar que, en función a sus raíces en la tradición yoruba, el candomblé guarda elementos muy fuertes de esta cosmovisión, sin embargo, la esclavitud y el contacto con la sociedad patriarcal occidental podría suponer una influencia en esta práctica dónde todavía la intersección de la mujer, negra y candomblecista deja algunos vacíos que merecen ser indagados. Como sostiene Bastide (1969), "[e]l americano negro vive en dos mundos, cada uno dotado de sus propias reglas; se adapta por una parte a la sociedad que le rodea, pero mantiene vivas en cambio, en otro terreno, las religiones de sus antepasados" (p. 120).

Quedará para futuros trabajos el desarrollo más profundo de otras perspectivas y debates sobre las prácticas de diversos candomblés y las nuevas apariciones de percusionistas mujeres en los terreiros de la actualidad del Brasil. 


\section{Referencias bibliográficas}

Baeta da Silva, L. M. (2005). A irmandade de Nossa Senhora da Boa Morte, uma perspectiva museológica e de gênero. En I Encontro de Estudos Multidisciplinares em Cultura, 14 y 15 de abril, Salvador de Bahia. Recuperado en: http://www.cult.ufba.br Barros Gama, L. (2009). Kosi Ejé Kosi Orixá: Simbolismo e representações do sangue no candomblé. [Disertación de Maestría, Universidade Federal de Pernambuco]. Recuperado en: https://repositorio.ufpe.br/handle/123456789/1116

Bastide, R. (1961). O candomblé da Bahia: rito Nagô. Colección Brasiliana, Vol. 313. São Paulo: Companhia Editora Nacional.

Bastide, R. (1969). Las Américas Negras. Madrid: Alianza Editorial.

Claudia de Oxalá. (Febrero, 2019). Entrevista.

Cordovil, D. (2016). Espiritualidades feministas: Relações de gênero e padrões de família entre adeptos da wicca e do candomblé no Brasil. En Revista Crítica de Ciências Sociais, 110 (pp. 117-140). Recuperado en: https://journals.openedition.org/rccs/6410?lang=es

Crenshaw, K. W. (2012). Cartografiando los márgenes: Interseccionalidad, políticas identitarias, y violencia contra las mujeres de color. En R. Platero (coord.). Intersecciones: cuerpos y sexualidades en la encrucijada, pp. 87-122. Barcelona: Bellaterra.

Ferreira Santos, E. (2009). O poder dos Candomblés. Perseguição e resistência no Recôncavo da Bahia. Salvador: Edufba.

Gilroy, P. (2014). El Atlántico Negro. Modernidad y doble consciencia. Madrid: Akal Hall, S. [1990]. (2010). Identidad cultural y diáspora. En Sin garantías. Trayectorias y problemáticas en estudios culturales, pp. 349 - 361. Popayán/Lima/Quito: Envión Editores/IEP/Instituto Pensar/ Universidad Andina Simón Bolívar.

Hodge Limonta, I. M. (2009). Cultura de resistência e resistência de uma identidade cultural: a santería cubana e o candomblé brasileiro (1950-2000). [Tesis de doctorado, Universidade Federal da Bahia]. Recuperado en: https://repositorio.ufba.br/ri/handle/ri/11253

Johnson, C. J. y Palmié, S. (2018). Religiones Afrolatinoamericanas. En A. De la Fuente y G. R. Andrews (Eds.). Estudios Afrolatinoamericanos: Una Introducción, pp. 513-566. Buenos Aires: CLACSO; Massachusets: Afro Latin American Researcher Institute. Harvard University.

Lugones, M. (2010). Colonialidad y género. En H. Cairo Carou y R. Grosfoguel (Eds.). Descolonizar la modernidad, descolonizar Europa: un diálogo Europa-América Latina (pp. 57-84). Madrid: IEPALA.

Minz, S. y Price, R. (2012). El origen de la cultura africano-americana: una perspectiva antropológica. México: Universidad Iberoamericana, A.C.; Universidad Autónoma Metropolitana y Centro de Investigaciones y Estudios Superiores en Antropología Social. 
Oyěwùmi, O. (2017). La Invención de las Mujeres. Una perspectiva africana sobre los discursos occidentales de género. Bogotá: Editorial En La Frontera.

Passos de Barros, I. R. (2017). O alagbê: entre o terreiro e o mundo. [Disertación de Maestría, Universidade Federal da Bahia]. Recuperado en: https://repositorio.ufba.br/ri/handle/ri/31383

Rocha, S.S. (2018). No candomblé mulher toca! A tradicão reinventada. En IV Congreso Internacional sobre culturas, memorias e sensibilidade: Cenários de Experiência Cultural Contemporânea. 21-23 de noviembre. Cachoeira, Bahia, Brasil. Recuperado en: https://www3.ufrb.edu.br/eventos/4congressoculturas/wp-

content/uploads/sites/19/2019/03/ROCHA-Sanara-S..pdf

Santos, T.M.S.A. (2009). O poder dos homens na cidade das mulheres. [Disertación de Maestría, Universidade Federal da Bahia]. Recuperado en: https://repositorio.ufba.br/ri/handle/ri/8667

Sardenberg, C. (1994). De sangrias, tabus e poderes: a menstruação numa perspectiva sócio-antropológica. En Revista Estudos Feministas; 2(2), pp. 314-344. Recuperado en: https://periodicos.ufsc.br/index.php/ref/article/view/16215

Segato, R. (2003). La invención de la naturaleza: familia, sexo y género en la tradición religiosa afrobrasileña. En Las Estructuras Elementales de la Violencia. Ensayos sobre género entre la Antropología, el Psicoanálisis y los Derechos Humanos. Buenos Aires: Universidad Nacional de Quilmes / Prometeo 3010.

Segato, R. (2011). Género, y Colonialidad: en busca de claves de lectura y de un vocabulario estratégico descolonial. En K. Bidaseca (org.). Feminismos y Poscolonialidad: descolonizando el feminismo desde y en América latina. Buenos Aires: Ediciones Godot.

Silva Bastos, I. (2009). A visão do feminino nas religiões afro-brasileiras. En Caos Revista Eletrônica de Ciências Sociais, 14, pp. 156-165. Recuperado en: https://periodicos.ufpb.br/index.php/caos/article/view/46959

Verger, P. (1985). A contribuição especial das mulheres ao candomblé do Brasil. En Documentos da Reunião de Peritos sobre "As sobrevivências das tradições religiosas africanas nas Caraíbas e na América Latina”. Culturas africanas (pp. 272-290). São Luís do Maranhão: UNESCO. Recuperado en: https://unesdoc.unesco.org/ark:/48223/pf0000071971 por

Vigoya, M. V. (2016). La interseccionalidad: una aproximación situada a la dominación. En Debate feminista, 52 (pp. 1-17). Recuperado en: https://www.sciencedirect.com/science/article/pii/S0188947816300603 